\title{
Mulemba
}

Revista Angolana de Ciências Sociais

4 (8) | 2014

Globalização, gestão e dinâmicas de desenvolvimento regional e local

\section{A longa marcha da modernidade em África. Saberes, intelectuais, democracia, de Jean Copans: Uma obra crítica sobre a objectividade do projecto africanístico, na longa duração entre tradição e modernidade}

Aida Pegado

\section{OpenEdition}

Journals

Edição electrónica

URL: http://journals.openedition.org/mulemba/309

DOI: $10.4000 /$ mulemba.309

ISSN: 2520-0305

Editora

Edições Pedago

Edição impressa

Data de publição: 1 novembro 2014

Paginação: 605-610

ISSN: 2182-6471

Refêrencia eletrónica

Aida Pegado, "A longa marcha da modernidade em África. Saberes, intelectuais, democracia, de Jean Copans: Uma obra crítica sobre a objectividade do projecto africanístico, na longa duração entre tradição e modernidade», Mulemba [Online], 4 (8) | 2014, posto online no dia 20 novembro 2016, consultado o 26 janeiro 2021. URL: http://journals.openedition.org/mulemba/309 ; DOI: https:// doi.org/10.4000/mulemba.309

Este documento foi criado de forma automática no dia 26 janeiro 2021.

Tous droits réservés 


\title{
A longa marcha da modernidade em África. Saberes, intelectuais, democracia, de Jean Copans: Uma obra crítica sobre a objectividade do projecto africanístico, na longa duração entre tradição e modernidade
}

\author{
Aida Pegado
}

\section{NOTA DO AUTOR}

Texto da apresentação pública da tradução portuguesa da obra do antropólogo, sociólogo e académico francês Jean COPANS, A longa marcha da modernidade africana. Saberes, intelectuais, democracia (Posfácio de Immanuel Wallerstein; tradução de Narrativa Traçada; revisão de Susana Ramos. Luanda, Edições Mulemba; Mangualde, Edições Pedago, 2014, 324p. [«Reler África»]), lido por ocasião das «Actividades alusivas a abertura do II semestre do ano lectivo de 2014», no anfiteatro da Faculdade de Ciências Sociais (FCS) da Universidade Agostinho Neto (UAN), em Luanda, no dia 20 de Agosto de 2014.

1 Jean Copans é um antropólogo e sociólogo francês, africanista, terceiro-mundista e marxista, tal como este se auto-intitula, sendo membro de várias instituições científicas universitárias, entre as quais o Centro de Estudos Africanos (CEA) da École des Hautes Études en Sciences Sociais (EHESS), em Paris (França). As suas investigações de terreno foram principalmente levadas a cabo no Senegal; mas foi também administrador do 
Centro de Pesquisas de troca e de documentação universitária em Nairobi (Kenya) de 1985-1989. De acordo com este, foi um período interessante para a sua carreira, devido a aquisição de um capital científico institucional e administrativo. As suas actividades foram também extensivas ao meio académico da África do Sul. Actualmente é professor emérito da Universidade de Paris Descartes.

2 Ao escrever a Longa marcha da modernidade africana Jean Copans produziu um ensaio alicerçado em conferências, comunicações, discussões, leituras e sobretudo nos saberes construídos através de uma longa prática de ensino e de investigação. Trata-se de um trabalho ensaístico, que é reconhecido pelos seus pares como um testamento, que é também uma autocrítica de um actor de uma geração de africanistas cujo sentido de missão fez do percurso do investigador um percurso militante, como aliás sublinha Immanuel Wallerstein no posfácio. Um percurso indissociável de trinta anos de investigações - décadas 1960, 1970 e 1980 - em torno de dinâmicas e da especificidade do objecto africanista.

3 Este ensaio estrutura-se em três partes. A primeira parte é um auto-retrato de um africanista europeu junto aos colegas das universidades africanas; a segunda é uma reflexão recorrendo à história sobre a especificidade do objecto africanista. A questão da tradição e da modernidade - que constitui a terceira parte do ensaio - tem como enfoque a problemática dos intelectuais e da democracia na sua relação de progenitura com a modernidade.

4 Este livro estabelece um diálogo com a África contemporânea, diálogo esse que se estende num arco temporal compreendido entre os anos 60 a 90 do século passado. Nesse diálogo, o autor justifica as razões que o levaram a escrever esta obra. Entre estas, sublinha como razão premente, ter constatado o acentuar do fosso entre os intelectuais africanos (colegas, estudantes, intelectuais e actores culturais) e os intelectuais ocidentais. $O$ eixo fundamental de reflexão incide sobre a evolução dos paradigmas teóricos e metodológicos, a natureza da história das sociedades africanas e a relação entre democracia e acção intelectual. Nesta senda, questiona a experiência democrática e a autonomia intelectual e cultural na África negra. É uma abordagem que qualifica de abstracta, para assim evitar exemplos cujo alcance epistemológico e político seria altamente questionável.

5 Ao analisar o trabalho dos africanistas franceses, Jean Copans assume uma posição crítica, considerando que os mesmos ambicionavam compreender África à luz da História Universal, mas que se enganaram relativamente ao seu objecto de estudo, ao procurarem racionalidades antropológicas num mundo natural e socialmente diferente.

Copans constata que ao longo dos trinta anos a que faz referência, os conhecimentos africanistas proliferaram, mas sem grandes efeitos uma vez que tais conhecimentos foram ultrapassados por novas temáticas como o desenvolvimento, o terceiromundismo, o etnocentrismo e o liberalismo. Prosseguindo na sua reflexão, o autor argumenta que estes africanistas franceses têm uma visão muito provinciana e paroquial do continente africano, seja a nível político ou a nível científico e cultural; e tal é devido a uma perspectiva restrita destes investigadores baseada em convicções de antigos colonos e investigadores que estão na moda. Consequentemente, a investigação desemboca na ignorância e/ou no enviesamento do conhecimento da realidade observada. 
7 No respeitante aos africanistas africanos, assim nomeados pelo autor, as suas interrogações incidem em saber até que ponto ser a crise africana uma crise de uma geração de intelectuais igualmente em crise; geração na qual é omissa uma dimensão fundamental, a saber, a intelligentsia africana. O efeito de ausência da intelligentsia africana leva Copans a seguinte constatação: os africanistas do sul são tratados de forma inconsciente ou cínica pelos seus pares ocidentais com uma simpatia que esconde uma postura paternalista.

8 A posição destes dois grupos de africanistas (ocidentais e africanos) face a África leva o autor a sugerir a reintrodução da problemática do poder e do saber como forma de compreensão do sentido da história africana moderna; e leva-o, igualmente, a questionar sobre a capacidade do continente de poder demonstrar um domínio do conhecimento de si, para além das ideologias da autenticidade e das ciências «por procuração».

9 Jean Copans prolonga a sua crítica às sociedades africanas que, segundo ele, transmitem nas suas formas de governação uma imagem de quem não se governa a si própria; considerando que uma tal situação é devida à carência de instrumentos sociológicos, culturais e intelectuais susceptíveis de produzir uma política autónoma e eficaz. Por essa razão, tornam-se dependentes do mimetismo/disfarce do Ocidente, reproduzindo os seus modelos. $\mathrm{O}$ autor defende que esses modelos, que constituem a modernidade do Ocidente foram criados de forma gradual e trabalhosa; os saberes políticos foram formalizados por pensadores como Rousseau, Nietzsche, Sartre passando por Kant, Hegel e Marx num contexto de humilhações, revoluções sociais, políticas e industriais.

Debruçando-se sobre o que acontece em África, Copans constata que os diversos actores africanos têm vindo a confundir invenção com imitação, importando modelos ocidentais que confirmam a visão colonialista de um progresso pronto a ser exportado e enxertado. A este mimetismo, o autor associa a gravidade de um mal que é a indolência empírica dos africanos na sua relação com o saber; indolência empírica que os distancia de conhecimentos abrangentes e complexos e de métodos cada vez mais sofisticados dos europeus - produção que é apanágio do Ocidente.

11 Inspirando-se nestas últimas considerações, Copans recorre à ironia. E argumenta que entre os melhores trabalhos dos investigadores do Ocidente e as imagens dos manuais africanos que contém silêncios, falsidades e censuras por parte dos poderes (e da intelligentia), permanece a dificuldade de se estabelecer uma relação entre a análise social e entre as escolhas ideológicas e as práticas políticas realistas e concretas. Cria-se assim um fosso e assiste-se a construção de um comportamento mimético fantasmático.

12 Na sua óptica, a abordagem destes fenómenos já não pode ser entendida à luz da teoria da dependência (recurso em voga 15 anos atrás). Teoria limitada nas explicações e compreensão que propõe do facto africano. As limitações da teoria da dependência e de outros paradigmas, reforça em Copans a convicção de que a África dos africanistas brancos e dos negros evidencia poucas ligações com a África dos povos africanos, na medida em que os saberes produzidos não concorrem para a resolução dos reais problemas dos países africanos. Perde-se assim o sentido das dinâmicas sociais que permanece escondido e vago. Ora, toda esta problemática condiciona e questiona possibilidades de emergência da modernidade africana.

13 Do ponto de vista deste antropólogo África deve deixar de ver a sua modernidade com as lentes do Ocidente, e consequentemente, inventar a sua própria modernidade e a sua 
própria relação com uma democracia política. Uma democracia que reconheça publicamente questões em processo de definição, tais como o género, a idade, a classe, a etnia e a nacionalidade; questões essas que reclamam a produção de saberes, que não podem ser dispensada.

Um outro nível de análise interroga o que o autor denomina «profundidades do campo», ou melhor, «trabalho de campo», trabalho em que há uma observação directa dos fenómenos sociais. A este propósito, inicia a sua reflexão nos anos 1960, onde a preocupação central é perceber como é que um antropólogo africanista europeu tem que sofrer metamorfoses para compreender a África negra e os seus problemas, numa década em que considera que o discurso científico em África era um discurso exógeno, quando havia necessidade de descobrir o "outro», isto é, descobrir a relação de alteridade.

Ao centrar-se no anos 1970, constata que estes são marcados pelo recrudescimento dos estudos africanos graças a uma intensa socialização e às reformas das universidades, na sequência das contestações de Maio de 1968 em França. Gradualmente, as ciências sociais «exóticas» vão saindo da sua condição periférica, enquanto que, concomitantemente, a situação política, social e cultural da África era preocupante e a produção veiculava, de modo inconsciente, respostas de leitores inquietos e confusos. A crítica passou a caracterizar a produção intelectual com o objectivo não de pôr fim à ciência, mas, pelo contrário, de pôr em marcha uma nova ciência. Nesta transição, Copans tem um papel activo enquanto africanista europeu marxista, cuja experiência relata ao longo da obra.

Quanto aos anos 1980, estes são marcados pelo abandono das ideologias, pelo reformismo, pela realpolitk, pelos limites de uma política científica. É neste período que o antropólogo participa nas actividades da revista francesa Politique Africaine.

17 Na segunda parte do livro, ao analisar o que denomina de «estudos africanos em movimento", aborda questões relacionadas com a sociedade, com a política e com a cultura, dando centralidade à dimensão antropológica.

Um outro ponto levantado pelo autor relaciona-se com a utilização de um eventual quadro conceptual ou metodológico aplicado ao estudo do continente africano. Em seu entender, esta problemática é de uma pertinência científica cada vez mais reduzida. Trata-se de uma questão quase clássica no mundo do conhecimento, que é de saber se existem ou não diferenças que justifiquem uma forma especial na aplicação do método científico quando se trata de estudos africanos.

19 Na terceira parte do livro, o leitor é confrontado com a posição ontológica ente tradição e modernidade. A este propósito, Jean Copans considera que a tradição e a modernidade (em que a razão é o filtro de todo o conhecimento) se ocupam dos paradigmas explicativos dos estudos africanos. Realça o avanço da tradição que foi feita através de antropólogos como Claude Lévi-Strauss e Georges Balandier, dando-lhe um cariz menos tradicional. Na sua análise, o marco que sinaliza o início da tradição é o período colonial. Esta assumpção é possível fazer devido a documentação disponível e que cobre esse período.

20 Em jeito de conclusão, Copans interroga-se sobre a possibilidade de se estar «rumo a uma "sociedade" de Estado». Para responder, faz um inventário das estruturas sociais africanas, dissertando sobre a modernidade, criando linhas de reflexão; analisa a construção da democracia; investiga a África negra e o discurso «revolucionário», tudo 
isto para nos dar a sua perspectiva da «longa marcha da modernidade em África». Deste modo, Jean Copans pesquisou factos, multiplicou observações, comparando, sistematizando, o que faz da obra um trabalho científico que vem contribuir para o avanço do conhecimento sobre os Estudos Africanos. É um antropólogo que se constrói com e contra a antropologia.

\section{AUTOR}

\section{AIDA PEGADO}

aidauan@gmail.com

Assistente do Departamento de Ciência Política da Faculdade de Ciências Sociais (FCS) da Universidade Agostinho Neto (UAN).

Doutorada em Estudos Africanos, na área de Política e Relações Internacionais numa perspectiva interdisciplinar, pelo Instituto Superior de Ciências do Trabalho e da Empresa - Instituto Universitário de Lisboa (ISCTE-IUL), tendo defendido a tese em 2014 com o trabalho Angola como potência regional emergente. Análise dos factores estratégicos. É Mestre em African Studies pela School of Oriental and African Studies (SOAS), London University e Fulbright em US Foreign Policy pela University of South Caroline, Estados Unidos da América (USA). É Assistente da Faculdade de Ciências Sociais (FCS) da Universidade Agostinho Neto (UAN), onde lecciona as cadeiras de História Política de Angola Contemporânea e Cooperação Internacional. Alguns dos trabalhos científicos produzidos têm os seguintes títulos: A comparison of the democratization process in Ghana and Angola, Londres, School of Oriental and African Studies (SOAS), London University, 1991; Ideologia e desenvolvimento económico em Angola, Lisboa, Instituto Superior de Ciências Sociais e Políticas (ISCSP), Universidade Técnica de Lisboa (2000); A classe política angolana, do nacionalismo à democracia, Lisboa, Instituto Superior de Ciências Sociais e Políticas (ISCSP), Universidade Técnica de Lisboa, 2002; O redimensionamento do Ensino Superior em Angola, no âmbito do projecto de investigação «O Ensino superior e os PALOP», patrocinado pela Fundação para a Ciência e Tecnologia. Lisboa, Instituto Superior de Ciências do Trabalho e da Empresa - Instituto Universitário de Lisboa (ISCTE- IUL), 2010; The social benefits from the oil companies: The Angola case study. Lisboa, Instituto Superior de Ciências do Trabalho e da Empresa - Instituto Universitário de Lisboa (ISCTE- IUL/ ECAS), 2013. 